\title{
Histórias que educam: dos velhos do quilombo à formação para a juventude - memória, saberes, tradição
}

\author{
Stories that educate: from the old of quilombo to the training for youth \\ - memory, knowledge, tradition
}

Historias que educan: de los viejos del quilombo a la formación para la juventud - memoria, saberes, tradición

\section{Pedro Fernando Santos ${ }^{1}$}

Escola Estadual Agrícola de Umãs (EAU), Professor Estatutário

https://orcid.org/0000-0002-2544-034X

http://lattes.cnpq.br/9577675074847730

Ana Lúcia Oliveira Aguiar ${ }^{2}$

Universidade do Estado do Rio Grande do Norte, Professora Adjunta IU

https://orcid.org/0000-0003-3626-2427

http://lattes.cnpq.br/4844989882232997

A memória pode ser conservação ou elaboração do passado, mesmo porque o seu lugar na vida do homem acha-se a meio caminho entre o instinto, que se repete sempre, e a inteligência, que é capaz de renovar

(William Stern).

Resumo: No processo de construção do conhecimento muitos povos, culturas e saberes foram margeados. Esse artigo é uma problematização proposta a uma pesquisa concluída no Programa de Pós-Graduação em Educação da Universidade do Estado do Rio Grande do Norte, que objetiva investigar as influências dos Saberes da Tradição concretizadas pelas "histórias dos velhos" da Comunidade Quilombola de Santana, em Pernambuco, para a formação da juventude dessa localidade. Como método, tem-se a História Oral, que examina o trabalho da memória como legado de tradição da comunidade. 0 estudo evidencia e denota a relação direta dos ensinamentos dos mais velhos para a formação dos mais jovens e, como base teórica, apoia-se, principalmente, em Bosi, Halbwachs, Pollak e Alberti para essa investigação.

Palavras-chave: Histórias de velhos. Quilombo. Saberes locais. Oralidade.

Mestre em Educação pela Universidade do Estado do Rio Grande do Norte; Especialista em Inclusão pela Rede Municipal de Educação de Mossoró.

2 Doutora em Sociologia pela Universidade Federal da Paraíba; Pós-doutora pelo Programa de Pós-Graduação em Educação da Universidade Federal do Ceará. 
Abstract: In the process of building knowledge many peoples, cultures and knowledges have been marginalized. This article is a problematization proposed to a research, completed in the Postgraduate Program in Education of the State University of Rio Grande do Norte, which aims to investigate the influences of the Knowledge of Tradition concretized by the "old people's stories" of the Quilombola Community of Santana, in Pernambuco, for the formation of the youth of that locality. As a method, we have Oral History which examines the work of memory as a legacy of community tradition. The study evidences and denotes the direct relation of the teachings of the elders for the formation of the younger ones and, as a theoretical basis, is based mainly on Bosi, Halbwachs, Pollak and Alberti for this investigation.

Keywords: Stories of old. Quilombo. Local knowledge. Orality.

Resumen: En el proceso de construcción del conocimiento muchos pueblos, culturas y saberes fueron margeados. Este artículo es una problematización propuesta a una investigación concluida en el Programa de Postgrado en Educación de la Universidad del Estado de Rio Grande do Norte, que pretende investigar las influencias de los Saberes de la Tradición concretadas por las "historias de los viejos" de la Comunidad Quilombola de Santana, en Pernambuco, para la formación de la juventud de esa localidad. Como método, se tiene la Historia Oral, que examina el trabajo de la memoria como legado de tradición de la comunidad. El estudio evidencia y denota la relación directa de las enseñanzas de los más viejos para la formación de los más jóvenes y, como base teórica, se apoya principalmente en Bosi, Halbwachs y Alberti para esa investigación.

Palabras clave: Historias de los viejos. Quilombo. Saberes locales. Oralidad.

Recebido em 18 de junho de 2018

Aceito em 24 de abril de 2019

Publicado em 15 de maio de 2019

\section{PASSOS PRIMEIROS E PRINCÍPIOS DO AGORA}

Como os Saberes da Tradição, expressos nas narrativas de vida de velhos da Comunidade Quilombola de Santana, PE, podem contribuir para a preservação e promoção de aprendizagens políticas dos mais jovens? Esse é o mote central da reflexão proposta neste texto.

Em uma comunidade quilombola os elementos identitários são forjados nas relações de parentesco, na significação com a terra (territorialidade), na história da ancestralidade e nas relações de pertencimento a um grupo étnico (quilombolas). A formação ideológica dos sujeitos que moram nessas comunidades obedece a ordens e elementos que, muitas vezes, 
são desconhecidos pela grande massa. Por isso, a pretensão de refletir sobre essas relações que se caracterizam pela educação não formal e perpassam pela formação social cidadã.

Na lógica universal do existencialismo de Sartre (1905-1980) para que algo tenha corpo é necessário haver a base que o sustente, que o fundamente e que o acentue no universo da realidade. Para ele, a existência é anterior à essência, tanto ontológica quanto epistemologicamente. Segundo Sartre (1960 apud SCHNEIDER, 2008), pode-se afirmar, em outras palavras, que deve haver uma conjuntura política, econômica e cultural em que os fenômenos humanos se desenvolvem. Assim, é primordial compreender que estes são realizados por pessoas concretas, sujeitos que se apropriam de sua situação e a transformam em algo, e que, portanto, nesse processo, a dimensão subjetiva é também determinante na realidade.

É isso o que chamamos de bases, neste trabalho, é o algo de cada processo do estrutural de uma pessoa ou de uma comunidade, por exemplo. Analogicamente ao que Sartre (1960 apud SCHNEIDER, 2008) aponta, é também assim que se concebem as "relações humanas" em uma coletividade. No caso de uma comunidade quilombola, que se institui identitariamente na coletividade, isso é indispensável, daí a importância da base. Portanto, ao se pragmatizar costumeiramente a vida, também se pragmatiza a forma de se relacionar, e, para isso, os fazeres moldam e conduzem essas relações de acordo com as margens do real, do humano, do esperado, do pretendido.

Agora, pensar todo esse leque de saberes, de relações, de posturas humanizadoras e desumanizadoras, de tradições e de sequência a serviço de uma formação é algo mais delicado, algo que precisa de uma análise mais apurada, no sentido de se tentar fazer uma conexão entre o aqui proposto e as teorias relacionadas. Para tanto, necessário se torna compreender também um pouco sobre os contextos onde essa proposta, esse espaço, esse lócus político, social, cultural e histórico estão inseridos. Qual é a gênese da reflexão? E, principalmente, qual é a gênese do local?

\section{A COMUNIDADE REMANESCENTE DE QUILOMBO SANTANA: 0 AROMA E O TOM DE UMA IDENTIDADE}

A formação das comunidades remanescentes de quilombos no sertão de Pernambuco ocorre, principalmente, por três operatórios históricos: de fluxos migratórios de outras comunidades quilombolas já existentes; da fuga de fazendas que mantinham o trabalho "semiescravo"; e do desalojamento do Arraial de Canudos (MONTEIRO, 2009), elemento mais forte na presença dos quilombos dos sertões. A principal fonte de enredo da história da Comunidade se constitui pela memória dos mais velhos. 
Aqui, dois aspectos se sobrepõem a qualquer observação e/ou posições que faremos ou que deveremos fazer neste texto. 0 primeiro é o fato da memória e da história oral como elementos históricos que se cristalizam nas falas de Bosi (1994, p. 54) e de Alberti (2005, p. 29) quando dizem, respectivamente, que “A memória é em si mesma, como subjetividade livre e conservação espiritual do passado" e "a história oral não é um fim em si mesma, e sim um meio de conhecimento." Nesse primeiro aspecto as autoras norteiam a importância do elemento e do método para a construção da história. 0 segundo diz respeito ao sujeito da memória e da narrativa oral e também a sua condição constante desde o passado até a atualidade, principalmente na comunidade em estudo, que é o sujeito "mais velho". Observe o enunciado por Halbwachs (1956 apud B0SI, 1994, p. 63, grifo nosso):

\begin{abstract}
Nas tribos primitivas, os velhos são guardiães das tradições, não só porque eles as receberam mais cedo do que outros, mas também porque só eles dispõem do lazer necessário para fixar seus pormenores ao longo de conversações com outros velhos, e para ensiná-los aos jovens a partir da iniciação.
\end{abstract}

Na caracterização de Halbwachs, os velhos agora imprimem sua narrativa, e, em suma, o que é posto é que em "parte" do século XIX um homem chamado Luciano, que era de uma região conhecida como Pajeú (orienta-se Rio Pajeú, PE) foi trabalhar na fazenda Passagem de Pedra, Município de Terra Nova (Sertão Central de PE) e lá "brigou" com pessoas porque mataram sua cachorra, e ele foge; supõe-se que ele matou a pessoa, vindo localizarse no Recanto. ${ }^{3}$ Ali foi mantendo relações com outros parentes e constitui-se o que é hoje a Santana, formada primordialmente pelas famílias Rocha, Luciano e Mariano. Observe-se que são nomes vagamente primeiros, não são portes de sobrenome, o que é uma marca evidente de ex-escravos.

0 território quilombola de Santana atualmente é composto por cinco pequenas localidades: Santana-de-Baixo (dos Pedros), Jurema, Olaria, Recanto e Livramento. A Comunidade apresenta moradias de mista fabricação (taipa, alvenaria), a produtividade das roças (em tempos de inverno) é de subsistência e o meio ambiente, que ainda se mantém preservado lapesar das agressões do Projeto de Integração do Rio São Francisco com Bacias Hidrográficas do Nordeste Setentrional), são fortes marcas da localidade. Por outro lado, o lugar tem um terreno geograficamente marcado por alterações de relevo e uma grande diversidade de flora e fauna. Santana apresenta um cenário tipicamente rural, apesar de certa proximidade com a sede do município (22 quilômetros de Salgueiro, PE).

Local que hoje é parte central do território da Comunidade Quilombola Santana. 
A economia do território está sustentada, em grande parte, nas atividades agropecuárias. 0 plantio ocorre nas roças familiares (trabalho no coletivo de núcleos familiares). Estas, em geral, estão localizadas em áreas de terra fértil e de proximidade com água.

Além dos aspectos relacionados à economia local, outro fator importante na caracterização da Comunidade de Santana é o seu patrimônio cultural (bens de ordem material, imaterial e emocional), como apontam Ataídes, Machado e Souza (1992, p. 11-१2), "que se apresentam, se caracterizam, são marcas e são apregoados ao povo, e aos fazeres do povo como identidade cultural."

Em resumo, pode-se dizer que é uma comunidade que, a partir de motivações internas, agressões e denominações externas, passou a desencadear sua etnogênese, procurando o fortalecimento de sua identidade quilombola e o reforço de suas práticas ancestrais, buscando se organizar para garantir sua reprodução social, desenvolver seu protagonismo cultural e se proteger das agressões impostas pelas iniciativas e estratégias do Estado brasileiro em incentivar a inércia política dos sujeitos que procuram a proficiência crítica do seu estado ativista.

\section{MEMÓRIAS QUE EDUCAM NA COMUNIDADE DE SANTANA}

Compreender as histórias, entender seus contextos, visualizar seus horizontes e pragmatizar aprendizagens a partir disso é a máxima das relações ancestrais que, instintivamente, o povo da Santana produziu durante toda a decorrência temporal e atemporal da existência da Comunidade.

Nesse aspecto, a memória, concretizada pela oralidade, constitui-se, dentro da história do lugar, o elemento principal dessa prática. E, ao ser narrada, rememorada, nos dá o legado do seu conceito e de seu caminho, e, de acordo com Alberti (1990), a oralidade centra-se na memória das pessoas e em seu potencial de rememorar o passado enquanto testemunhas do vivido. Aprofundar isso para o universo das realizações humanas seria afirmar a ótica de Vansina (2010) ao propor que a oralidade é a força de uma atitude e o reforço de uma habilidade invocada para um dado específico de seu poder e de sua condução da história... Os ditos agora se pragmatizam e recompõem a tradição.

Podemos, então, compreender a memória como a manifestação do passado, por meio de uma construção psíquica e intelectual de fragmentos representativos desse mesmo passado, nunca em sua totalidade, mas parciais em decorrência dos estímulos para a sua seleção. 
Essa é a garantia ratificada de que as narrativas formam, para o povo e no povo, a concepção coletiva do saber da tradição e emitem para a comunidade os elementos da construção da identidade coletiva, das aprendizagens políticas e da construção de novas experiências. Vale destacar, como forma de valor da narrativa do outro para si, o que Bosi (1994, p. 85) nos diz, que “A arte da narração não está confinada nos livros, seu veio épico é oral. 0 narrador tira o que narra da própria experiência e a transforma em experiência dos que o escuta."

Esse é o poder e a mágica da história oral em produzir para os outros experiências a partir de outras experiências, de outros momentos, de outras vidas com fazeres iguais deslocados não somente no tempo, mas transpondo fronteiras políticas, barreiras sociais, aspectos culturais, imaginando divisões geográficas, atravessando limites do imaginário de cada pessoa ou povo. Para Bosi (1994, p. 84), “o narrador vence distância no espaço e volta para contar suas aventuras [...] suas peripécias que tem significado." Para isso, observemos o que Dona Vilani, uma "velha do quilombo", nos diz:

\begin{abstract}
[...] eu já aprendi cum os outros... Icom outros velhosl, do meu tempo que eu era criança, do meu tempo de infância lbaixinhol é do tempo de infância qui num era cuma hoje. Ai eu, depois, eu tô sempe hoje também dizeno laos outrosl como deve fazer. (Maria Vilani. Entrevista realizada em 03 de abril de 2014) (informação verbal). ${ }^{4}$
\end{abstract}

A fala dessa mulher nos caracteriza a retomada de um passado, a transcorrência no tempo, a presentificação desse passado, a posição imediata do "hoje" e a perspectiva do futuro. Para esse povo a fala se conduz dentro de um "continnum" que the sombreia as emoções não somente do dito, mas da pureza e poder do dito; solta-se o "divino" da palavra e transcende de um "eu" para um "nós" de um ser coletivo (BÁ HAMPATÉ, 2010). Essa mobilização de habilidades e ancestralidades contidas nesse aspecto não é só praticamente o deslocamento espacial, porém, com isso, se reproduz toda uma gama de ressignificações capazes de produzir e/ou reproduzir saberes sociais que darão nortes para as futuras ações individuais e da coletividade de pertença do sujeito "que escuta" a narrativa. Isso é a pragmatização da transmissão dos saberes e das relações que perdurou ancestralmente na Comunidade.

Assim a constituição dos ordenamentos do "hoje", segundo a fala de Dona Vilani e Bosi (1994), se dá pela rememoração seletiva do que vem de outro passado, provavelmente rememorado por outros sujeitos. No caso, isso fica bem nítido quando ela o enfatiza. Para a Comunidade Quilombola de Santana, a memória concretizada na narrativa dos velhos nos dá o 
aprofundamento necessário para compreendermos a relação da história local com a memória local, há uma junção direta, na qual a fronteira nem sempre será visível.

\section{NA ESTEIRA DA RESISTÊNCIA DA COMUNIDADE DE SANTANA}

As Comunidades Tradicionais, como são nomeadas atualmente, através dos tempos sempre se distinguiram, de uma forma ou de outra, por algum caráter que não thes permitiu emergir no universo da existência comum dos lugares, dos povos, das regiões, dos espaços de convivência, enfim, daquilo que socialmente era dinâmico e existia pela presença de elementos mínimos de uma organização.

No caso de uma comunidade remanescente de quilombo, esse aspecto tradicional se formata pela sua gênese e, como é notório, historicamente, esse processo foi muito difícil, estagnante, dolorido e sangrento, carregado de forças sociais contrárias a sua existência. Os quilombolas mais velhos de Santana costumavam dizer que sua existência era "proibida", eles que eram "teimosos" em existir. Então, essa existência precisou criar e recriar formas de coexistir com esses elementos "dificultores", procurou se formatar para se sobrepor às investidas das inúmeras "razões contrárias" para seguir perpetuando sua história e garantindo sua existência através dos tempos.

A cada tempo, "novos dificultores" demandavam também novos comportamentos sociais, culturais, políticos e éticos; eram inúmeros esses elementos que investiam contra o povo. Cotidianamente, um novo modelo de vida, uma forma ignorante de comportamento busca ditar as atitudes mundiais e, subjetivamente, ataca aquilo que foi politicamente instituído e que vai de encontro a ele. A globalização é essa nova materialização que danosamente invade a identidade e ataca grupos étnicos que buscam fundamentar essa identidade nas formas ancestrais de sua existência. Essa globalização se concretiza no "mundialismo capital" que é a personificação moderna dessa forma politicamente danosa e socialmente disfarçada, que se aproveita das chamadas "ferramentas da modernidade" para conseguir seu propósito, permutando entre suas duas faces, aquela para o sujeito político e a outra para o sujeito ainda em formação, como bem expressa o professor Valdir Santana:

[...] a globalização fez/faz emergir antigas lutas por identidades, disputas étnicas e reivindicações de grupos segregados historicamente. Os novos espaços/tempos criados pelo processo de globalização, atrelados ao desenvolvimento e expansão dos "meios telemáticos", conduzem a uma nova lógica de percepção do espaço, e do Estado-Nação que, no discurso da modernidade, se constituíam como entidades "concretas" e definidoras de uma identidade, que se apresentava unificada e imutável. (SANTANA, 2009, p. 2). 
Pois, se é essa a lógica da globalização, também essa é a lógica da mundialização que postula para aqueles que são atraídos por ela as formas de comportamento e atitudes, fazendo com que a juventude, por exemplo, caia diante dos seus apelos.

A televisão, a internet, a música de massa, a imprensa apolítica, as novas formas de trabalho, os "modernos paradigmas educacionais" são algumas dessas ferramentas que se autopromovem e são inerentemente atrativas a um público - a juventude. Nesse caso, nas comunidades quilombolas, e especificamente na Santana, esse público não está livre dessa ameaça, ao contrário, os governos instituem "políticas de inclusão" que promovem, alienadamente, o contato dos jovens com essas ferramentas.

0 risco pode ser a confusão no diálogo entre a identidade desses sujeitos, ainda em formação, com esses atrativos mundialistas. Isso pode afetar esses jovens de tal forma que eles podem se caracterizar de acordo com o propósito da globalização, como observa Fleuri (2003, p. 9): "[...] globalizar [...] pode significar homogeneizar, diluindo identidades e apagando as marcas das culturas ditas inferiores, das raças, etnias, gêneros, linguagens, religiões e grupos, conforme a lógica das narrativas hegemônicas'."

É aí onde reside o problema, o conflito das identidades diante dos apelos do "mundialismo capital" que pode influenciar na formação dos jovens da Comunidade a ponto de descaracterizá-los como quilombolas e provocar a negação dos saberes tradicionais, podendo levar à extinção das relações humanas que ancestralmente foram instituídas e que sempre foram as bases sociais da Comunidade.

Visto isso, e de posse dessa consciência, emerge, cada vez mais urgente, a necessidade da reflexão aqui proposta, mesmo já havendo visivelmente na Comunidade um apreço pelas relações que se constituíram ancestralmente apregoadas nos fazeres e no viver cotidiano das pessoas. Resta saber, então, até que ponto e como essa ancestralidade, limitada neste estudo pelas narrativas orais de pessoas da Comunidade, termina por contribuir mais e mais para a formação dos jovens.

\section{NA TRILHA DE UMA REFLEXÃO}

Como já expresso anteriormente neste texto, para se ter maior propriedade nessa análise, é essencial propormos um diálogo entre o aspecto das narrativas orais e as teorias mais acentuadas e mais marcadas, com relação ao método e suas contribuições para a produção de saberes e de lógica didática do conhecimento. 
Partimos aqui das prerrogativas dos estudos, principalmente, de Michael Pollak Maurice Halbwachs, Ecléa Bosi e Verena Alberti, para a centralidade da discussão aprimorando sempre o foco: narrativas orais com fortes traços étnicos e identitários para a produção de formação político-social em jovens quilombolas.

Hall (2005), em um estudo intitulado A ldentidade Cultural na Pós-modernidade, dedicou atenção pretenciosa e focal para o aspecto da construção, significação ou ressignificação da identidade. Nesse trabalho, ele aborda de perto a questão de uma "crise de identidades" e torna evidente que estruturas do passado estão sendo deslocadas e ressignificadas para a produção de identidade mais fragmentada em oposição àquela acentuada no universal. Segundo Hall (2005), é notória a carência de uma identidade fundada em contextos mais atuais e mais locais, porém ele nos alerta sobre a complexidade de conceitos que mobilizamos para isso.

Bem, pode até ser que a reflexão de Hall não nos dê, para este estudo, o conceito ou o caráter de uma identidade pautada em etnicidade, mas, certamente, nos remete à necessidade desse tipo de identificação, e, para este estudo, isso já basta. Para tanto, a ideia aqui é a construção da identidade a partir da referência local; no caso dos quilombolas de Santana esse referencial está composto pelos saberes da tradição que se promovem nas histórias dos velhos. Precisamos, pois, conceber esses saberes, assim, notaremos a posição do professor Valdir Santana:

[... concebemos [...] os "saberes da tradição" como um conjunto de conhecimentos sujeitos a transformações que emergem das dinâmicas históricas e das mudanças que se operam na cultura. Nesse sentido, a tradição não é pensada como um corpus fechado de saberes que persiste ao tempo, de forma inalterada. Da mesma forma, não queremos negar a reprodução social dos saberes, uma vez que entendemos que o processo de transmissão de uma tradição implica numa reprodução social que convive com a mudança. (SANTANA, 2009, p. 89, grifo nosso).

Santana (2009) traz a possibilidade de construção da identidade em três aspectos, que, no nosso caso, abordaremos como dimensões concretas: "corpos não fechados de Saberes" - dimensão política; "a reprodução social dos saberes" - dimensão do tempo social; e, "transmissão de uma tradição" - dimensão da manutenção cultural.

Desse modo, levando-se em consideração a dimensão política, trata-se, pois, da construção ou afirmação de uma identidade coletiva a partir da identidade individual, pela sequência da história do "outro". Para corroborar essa perspectiva, Pollak (1992, p. 5) versa afirmando: 
A construção da identidade é um fenômeno que se produz em referência aos outros, em referência aos critérios de aceitabilidade, de admissibilidade, de credibilidade, e que se faz por meio da negociação direta com outros. Vale dizer que memória e identidade podem perfeitamente ser negociadas, e não são fenômenos que devam ser compreendidos como essências de uma pessoa ou de um grupo.

Considerando, então, que essa primeira ideia - a identidade étnica - é um elemento basilar para uma autoafirmação, e postulado para um possível ativismo político, logo, nessa perspectiva, é relevante estudar como se produz essa identidade, e, pensando como enuncia Pollak (1992), essa construção necessariamente precisa partir do principal lócus social dos sujeitos - sua comunidade de pertença, seu ethos e dos seus pares em alteridade -: o "outro". Vejamos nas falas dos entrevistados que a referência ao "outro" é uma constante, demonstrando que essa identidade é posta de um para o "outro" e, principalmente, um "outro" pretérito, porém presentificado na memória de que se referencia: "[...] meu pai contava que Antonio Luciano era o pai dele, meu avô chegou aqui como fugitivo, meu pai contava essa história." (OLIVEIRA JUNIOR, 2009, p. 59, grifo nosso).

Nesse "continnum" a narrativa invoca o "outro", como em uma ação polifônica na qual cada um principia o que vem.

\footnotetext{
Começou com Antônio da Rocha meu bisavô, era o avô de minha mãe. Morava lá na Jurema. Este terreno era dele até lá no Angico. Aí o homem morreu, ai dividiu com os filhos e foi criando. [...]

Ele era João Mariano dos Santos, foi uma pessoa qui eu me espelhei bastante apesar de que quando ele faleceu eu só tinha oito anos de idade, mas ele era uma pessoa qui eu conseguia observar a preocupação que ele tinha com as pessoas e, até mesmo, com o meio ambiente; cuidava do riacho, plantava fruteira. Eu ouvia dizer assim: eu sei que não vou vê essa manguera colocar fruto, mas fica ai pra vocêis. .... Ele é uma pessoa que não passou, ele ficou na história... (OLIVEIRA JUNIOR, 2009, p. 60).
}

Aplicando a afirmativa de Pollak (1992) ao caso da identidade quilombola que é inerentemente coletiva, essa negociação de "si" com o "outro" acontece também naturalmente, visto que, contemporaneamente, a necessidade da afirmação de uma identidade tem se tornado cada vez mais necessária. Esse rol de expressões trazidas por Oliveira Junior (2009) e tensionadas por Pollak (1992) podem ser compreendidas pelo viés da cosmoafricanidade, que elucida: "na visão de mundo africana tudo está em tudo, isto é, tudo se complementa. [...] A integração possibilita a conjugação das diferenças. [...] 0 que há são possibilidades diferenciadas de arranjos sociais, culturais, etc." (OLIVEIRA, 2006, p. 117 apud PETIT, 2016, p. 663). 
Perceba que as expressões do "eu" são carregadas do "outro" como fruto de uma alteridade: "[...] o outro é bem-vindo e bem tratado [...] Considera-se que sempre há espaço para todos, mais um, não é problema, pelo contrário, o outro é desejado. “Dessa forma, o diálogo com o outro instaura mais uma vez uma adaptabilidade, um convívio, uma troca." (PETIT, 2016, p. 665-666).

É importante também salientar que essa negociação não é puramente amistosa, nem especificamente dentro das temporalidades convencionais e envolve disputas e superposições. Isso se torna visível pelos conflitos de discurso sobre discursos, pragmatizado pelas histórias orais de cada indivíduo, para a aceitação ou refutação da coletividade, a partir do indivíduo ou da convergência de uma história geral e coletiva. 0 próprio Pollak (1992) fala dessa ação "agonística" que, segundo ele, os sujeitos rememoram suas histórias a partir de interesses do vivido, a partir de significâncias que, muitas vezes, não recebem do grupo o fundamento, pois, na verdade, fazem parte de uma memória individual.

Um segundo aspecto da formação é a dimensão do tempo social que na verdade traz consigo o "universo do discurso", o "universo de sentido" e a prática da reprodução social do saber contido na experiência de uma vida, de uma tradição. Como promover o legado de uma identidade étnica pautada pela presença do "outro"? 0 tempo social pode construir as ferramentas para isso, pois ele se configura em algo maior, de máxima força, de fronteiras alargadas que se fazem também pela existência de outros tempos, como afirma Bosi (1994, p. 418): “0 tempo social absorve o tempo individual que se aproxima dele." Assim podemos dizer que depois de construída ou afirmada essa identidade ela agora precisa socialmente ser colocada em prática ativa, e o princípio dessa prática é se tornar ouvinte das narrativas, partindo do indivíduo para a coletividade e tramar, tecer redes, promover conexões diversas e se fortalecer para garantir a universalização desse tempo social e do "universo de discurso" e de "sentido" aos povos constituintes dos saberes e de tradição, como expõe Franco (2003). De acordo com ele quanto mais tramada por dentro (por redes sociais) for uma localidade e quanto mais conectada para fora ela estiver, maior será o seu "poder" de gerar padrões replicáveis de comportamento, maior abrangência política terá.

Na Comunidade de Santana o tempo social (discurso e sentido) se concretiza na união, na aprendizagem de "um" para "outro", na ressignificação da prática tradicional. A narrativa de Dona Raimunda Rosa mostra a alteridade de um tempo para outro:

É, eu insino, eu digo a eles cuma era no passado, cuméra qui nossos pais fazia cum nois, cum'era qui insinava a nois, l... Se a gente insinar, se a gente quiser explicar direitinho cuma a gente vivia, cumera qui a gente fazia, é bom, pruque era bom. (Raimunda Rosa. Entrevista realizada em 02 de abril de 2014) (informação verbal). 
Do mesmo modo Dona Vilani fala dessa união: "L...] ser unido, é respeitar, é prestá atenção qui é qui aqueles mais véi tão dizeno, pá vê se consegue andar naquele caminho um pouco." (Maria Vilani. Entrevista realizada em 03 de abril de 2014) (informação verball.

"0 ensinamento não é sistemático, mas ligado às circunstâncias da vida. Este modo de proceder pode parecer caótico, mas, em verdade, é prático e muito vivo. A lição dada na ocasião de certo acontecimento ou experiência fica profundamente gravada na memória." (VASINA, 2010, p. 183). Assim os operatórios dessa ação se fazem e se refazem dentro das estruturas sujeito-tempo.

Nesse sentido, o tempo social pode ressignificar essas histórias, pela aproximação do individual com o coletivo. Assim, nota-se que esse povo busca, mesmo dentro das adversidades, preservar sua capacidade cultural para promover seu papel histórico "padrões replicáveis". Mas, sempre observando os contextos temporais. São esses "padrões replicáveis" que vão ser peças de uma engrenagem para a prática da ação política e social da juventude e, consequentemente, a formação de atitudes cidadãs.

A terceira dimensão importante, nesse processo, é a manutenção cultural da tradição. Retomando a ordem lógica, pode-se pensar que depois da identidade formada ou afirmada, depois de colocada em prática, a ação política do jovem seja, agora, a de "sentar para ouvir a história", porque sua tarefa será a de manter, promover e transmitir os saberes da tradição como se estivesse concluindo, assim, sua sequência de aquisição de conhecimentos políticos e sociais no transcorrer do processo de formação. Bosi (1994, p. 90) remata essa ideia aqui exposta quando afirma que "a história deve reproduzir-se de geração a geração, gerar muitas outras cujos fios se cruzem, prolongando o original, puxado por outros dedos." A fala de Dona Vilani mostra essa necessidade de manter e seguir promovendo a história, os valores e a tradição social de uma cultura por meio da narrativa. "É importante insiná o que aprendi. Eu aprendi cum os mais véi, e é importante que os ôto insine também. Se o mais novo quiser aprender é bom [...] Cuma nois aprendemo." (Maria Vilani. Entrevista realizada em 03 de abril de 2014) (informação verbal).

Entende-se que aqui o ciclo ganha poder, mesmo com todas as investidas externas, citadas anteriormente, esse processo pode "replicar" relações humanas ancestralmente construidas na Comunidade e garantir a produção e a reprodução social, cultural, histórica, pessoal, interpessoal, territorial, ambiental, enfim, tudo que foi "base do existencialismo" para a vida individual e coletiva do lugar.

De acordo com Halbwachs (1990), a memória coletiva ganha força e dá tom à tradição pela relação do sujeito com seu grupo de pertença, a partir das configurações que a história dá em analogia com o que as lembranças the propiciam. Ai funda-se a práxis da ação jovem que ao percorrer toda a trajetória das narrativas dos outros, para se dizer quem 
é, para agir segundo sua identidade, agora, formata na síntese dos "outros" também sua narrativa e, historiando, vai construindo outras histórias de outros sujeitos.

Obviamente, todas essas ações, todas essas atitudes de alteridade, toda a potencialidade identitária das pessoas da Santana são, evidentemente, consideradas pelo povo de lá como algo muito natural; é tanto que essa exposição que aqui observamos só pode ser vista e percebida em um trabalho como este, uma garimpagem sensivel de outras sensibilidades locais. Segundo Arendt (2007), o labor, o trabalho e a ação são atividades condicionadas à humanidade; nesse caso, na Comunidade de Santana os fazeres, as múltiplas relações e a própria existência social, cultural e política denotam outra condição - a dimensão política. É essa dimensão que pragmatiza todas essas construções históricas e humanas. Por mais plurais que sejam as memórias e os ecos produzidos por elas, valem-se daí a história coletiva, que se forja dentro do agonismo político do povo, que também é comum nesse tipo de processo humano.

A própria Arendt (2007) aponta esse processo como "vita activa", designando posturas, apegos e relevâncias das pessoas quanto aos saberes que os velhos materializam em suas narrativas e legam para toda a comunidade - o princípio da alteridade social, política, cultural, filosófica, identitária, coletiva... - Enfim... designando um leque de motivações para a composição do roteiro da vida na Santana.

Portanto, o comportamento das pessoas de qualquer forma "se condiciona" pelas transformações ou "é condicionado" pelo ativismo das transformações, mas de qualquer maneira haverá dinâmica social, não há como fugir dela. Para as comunidades tradicionais quilombolas, isso de dinâmica do tempo não é, nitidamente, levado em conta como foco das relações, mas é feito pelo instinto natural de proteção e de garantia da soberania de vida.

\section{DO CANTO ÀS CONSIDERAÇÕES}

Quando se tratam das histórias orais de "velhos" de uma comunidade remanescente de quilombo que se localiza no campo, pode-se perceber aí que há um recorte suficiente para notabilizar uma forma de educação que não se encontra estritamente na escola, mas foge às fronteiras institucionais e transcede para espaços sociais. Portanto, o que se aborda é uma forma de conhecimento não necessariamente escolarizado. E, mais, pode-se perceber que é uma proposta de formação para o exercício da cidadania política a partir das fronteiras de "si" para o "outro", das histórias locais para a composição do "eu". Então essa é uma forma de educação a partir da identidade, ordenada principalmente pela alteridade. 
É uma constante no texto a relevância do todo constituído pelos fragmentos de cada um, pelos pedaços do passado dos outros, pelas lembranças ainda vivas, pelo reconhecer do "outro". Tudo isso é o tecido de um saber, de uma tradição, de histórias que se formaram e que legam ao "outro" a localização humana de coletivo, de pertença e de sujeito de uma ação política que ocorreu em um tempo, em um espaço e se reproduz socialmente.

Desse modo, o apanhado dessas constatações, e de posse da propriedade fruto da conexão conceitual, factual e de observações, com as análises permitidas por Bosi, Halbwachs e Pollak e outros, fica mais fácil elucidar o mote da reflexão aqui proposta. 0 fato é que as teorias e as falas enumeradas nos remetem para a posição satisfatória de que há, sim, uma contribuição dos saberes da tradição nessa formação e até em que momentos isso vai acontecer.

\section{REFERÊNCIAS}

ALBERTI, V. História oral: a experiência do CPDOC. Rio de Janeiro: Fundação Getúlio Vargas, 1990.

ALBERTI, V. Manual de história oral. 3. ed. Rio de Janeiro: Editora FGV, 2005.

AREDNT, H. A condição humana. Tradução: Roberto Raposo. 10. ed. Rio de Janeiro: Forense Universitária, 2007.

ATAIIDES, J. M.; MACHADO, L. A.; SOUZA, G. G. Desenvolvimento e direitos humanos: a responsabilidade do antropólogo. Campinas, SP: UNICAMP, 1992.

BÁ HAMPATÉ, A. A tradição viva. In: KI-ZERBO, J. (ed.). História Geral da África, I: Metodologia e pré-história da África. 2. ed. Brasília, DF: UNESCO, 2010.

BOSI, E. Memória e Sociedade. Lembranças de velhos. 3. ed. São Paulo: Companhia das Letras, 1994.

FLEURI, R. M. (org.). Educação Intercultural: mediações necessárias. Rio de Janeiro: DP\&A editora, 2003.

FRANCO, A. de. A revolução local: globalização, glocalização, localização. São Paulo: Cultura/AED, 2003.

HALL, S. A identidade cultural na pós-modernidade. 10. ed. Rio de Janeiro: DP\&A Editora, 2005.

MONTEIRO, V. S. V. Canudos: guerra de memória. Revista Mosaico, Rio de Janeiro, ano 1, n. 1, p. 84-93, 2009. Disponivel em: http://cpdoc.fgv.br/mosaico. Acesso em: 16 jan. 2014.

OLIVEIRA JUNIOR, G. B. Relatório antropológico de caracterização histórica, econômica, ambiental e sociocultural da comunidade remanescente de quilombo de Santana. Salgueiro, PE: Ministério da Integração Nacional, 2009. 
HALBWACHS, M. A memória coletiva. Presses Universitaires de France, 1990.

PETIT, S. H. Práticas pedagógicas para a lei n` 10.639/2003: a criação de nova abordagem de formação na perspectiva das africanidades. Educação Foco, Juiz de Fora, v. 21, n. 3, p. 657-684, dez./set. 2016. Disponível em: http://ojs2.ufjf.emnuvens.com.br/edufoco/article/view/19874/10621. Acesso em: 15 mar. 2019.

POLLAK, M. Memória e ldentidade Social. Estudos Históricos, Rio de Janeiro, v. 5, n. 10, p. 200-212, 1992.

SANTANA, J. V. J. A face simbólica dos "saberes da tradição" e a produção de identidades no contexto do povo indígena Kiriri. Revista Espaço Acadêmico, n. 101, 2009. Disponível em: www.revipsi.uerj.br/ v8n2/artigos/pdf/v8n2a13.pdf. Acesso em: 20 nov. 2014.

SCHNEIDER, D. R. 0 método biográfico em Sartre: contribuições do existencialismo para a psicologia. Revispsi/UERJ, Rio de Janeiro, ano 8, n. 2, p. 289-308, $1^{\circ}$ sem. 2008. Disponível em: www.revipsi.uerj.br/ v8n2/artigos/pdf/v8n2a13.pdf. Acesso em: 15 jan. 2014.

VANSINA, J. A Tradição Oral e sua Metodologia. In: KI-ZERBO, J. (ed.) História Geral da África, I: metodologia e pré-história da África. 2. ed. Brasília, DF: UNESCO, 2010.

Endereços para correspondência: Rua Dom Pedro II, 92, Bairro Paredões, 59618-110, Mossoró, Rio Grande do Norte, Brasil; oliveiraaguiarpetro@gmail.com 
